\title{
Relief of pain in acute herpes zoster by nerve blocks and possible prevention of post-herpetic neuralgia
}

\author{
[Le soulagement de la douleur de l'herpès zoster aigu et la prévention possible de la \\ névralgie post-berpétique par des blocages nerveux]
}

Douglas Hardy MD FRCPC

Purpose: This report describes two cases of acute herpes zoster $(\mathrm{AHZ})$ treated by nerve block resulting in immediate pain relief and possible prevention of post-herpetic neuralgia ( $\mathrm{PHN}$ ).

Clinical features: Two elderly females with $\mathrm{AHZ}$ of cervical dermatomes and severe pain received deep cervical and greater occipital nerve blocks with a local anesthetic, epinephrine and steroid. In both patients, pain resolved immediately and permanently (one year follow-up) after a single treatment.

Case \# I: A 79-yr-old female with a mechanical mitral valve and anticoagulated with warfarin presented with $\mathrm{AHZ}$ of 17 days duration of the right C2, 3, 4 dermatomes and severe pain. A stellate ganglion block was not performed because of anticoagulation. Rather, a deep cervical root block at C3 and a greater occipital nerve block were performed with bupivacaine, epinephrine and methylprednisolone. No adverse events were evident. Case \#2: A 73-yr-old female with a history of osteoarthritis and Meniere's disease presented with $\mathrm{AHZ}$ of seven days duration of the left $\mathrm{C2}, 3$, 4 dermatomes and severe pain. Deep cervical root blocks at $\mathrm{C} 3$ and $\mathrm{C} 4$ and a greater occipital nerve block were performed with bupivacaine, epinephrine and methylprednisolone. Side effects of dizziness, hoarseness, hypertension and Horner's syndrome resolved in a few hours. A mild sensation of itching persisted for two weeks.

Conclusion: This report illustrates the potential of nerve blocks in severe $\mathrm{AHZ}$ to treat acute pain and possibly prevent $\mathrm{PHN}$.
Objectif : Décrire deux cas d'herpès zoster aigu (HZA) traités par blocage nerveux résultant en un soulagement immédiat de la douleur et une prévention possible de la névralgie post-herpétique (NPH).

Éléments cliniques : Deux femmes âgées souffrant d'HZA des dermatomes cervicaux et de douleurs sévères ont reçu un bloc des nerfs cervical profond et grand occipital avec un anesthésique local, de l'épinéphrine et des stérö̈des. Dans les deux cas, la douleur a été soulagée de façon immédiate et permanente comme l'a montré le suivi d'un an.

Cas no 1: Une femme de 79 ans, porteuse d'une valvule mitrale mécanique, anticoagulée avec de la warfarine, souffrait depuis 17 jours d'un HZA au niveau des dermatomes droits C2, 3, 4 et de sévères douleurs. L'anticoagulation ne permettant pas de bloc du ganglion stellaire, on a plutôt opté pour un bloc de la racine cervicale profonde à C3 et un bloc du grand nerf occipital avec de la bupivacaïne, de l'épinéphrine et de la méthylprednisolone. Aucune évidence d'événement indésirable n'a été notée. Cas no 2 : Une femme de 73 ans aux antécédents d'ostéoarthrite et de maladie de Ménière, a consulté pour un HZA installé depuis sept jours aux dermatomes gauches $C 2,3,4$ et pour de sévères douleurs. Des blocs de la racine cervicale profonde à $\mathrm{C} 3$ et $\mathrm{C} 4$ et un bloc du grand nerf occipital ont été réalisés avec de la bupivacaïne, de l'épinéphrine et de la méthylprednisolone. Les effets secondaires, étourdissement, enrouement de la voix, hypertension et syndrome de Claude Bernard-Horner, se sont résorbés en quelques heures. Une légère sensation de prurit a persisté pendant deux semaines.

Conclusion : Cet article illustre le potentiel des blocages nerveux dans des cas d'HZA sévère pour traiter la douleur aiguë et possiblement prévenir la NPH.

From the Department of Anesthesiology, University of Ottawa, Ottawa, Ontario, Canada. Address correspondence to: Dr. Douglas Hardy, Department of Anesthesiology, The Ottawa Hospital-Civic Campus, 1053 Carling

Avenue, Ottawa, Ontario KlY 4E9, Canada. Phone: 613-761-4169; Fax: 613-761-5209; E-mail: dhardy@ottawahospital.on.ca Accepted for publication February 4, 2004.

Revision accepted November 8, 2004. 
A CUTE herpes zoster (AHZ) is a localized disease that results from reactivation of an endogenous varicella zoster virus infection that has persisted in latent form within sensory ganglia following an earlier attack of varicella. Its frequent occurrence in the elderly may be related to a decrease in cell-mediated immunity with advancing age. ${ }^{1}$ A painful pre-herpetic neuralgia ( $\mathrm{PHN}$; prodrome) may precede the rash by a few days. AHZ can produce debilitating pain, especially in the elderly. Origin of the pain is thought to be from inflammation and damage to the dorsal root ganglion and peripheral nerve. This is followed by changes in dorsal horn and "centralization" of pain.

Rowbotham estimates that there are up to one million new cases of AHZ each year in the United States, each costing the health care system an estimated $\$ 8,500$ US. $^{1}$ AHZ may progress to $\mathrm{PHN}$ (defined as pain at one month from rash onset) in up to $75 \%$ of patients $75 \mathrm{yr}$ of age or older. ${ }^{2}$ Once PHN is established, it can be difficult to manage effectively, making this complication the most compelling reason to treat AHZ. ${ }^{3}$ Nerve blocks are an accepted therapy for pain relief in AHZ, however their efficacy in the prevention of PHN remains contested. ${ }^{4}$ This article presents two cases in which nerve blocks administered during the course of AHZ provided lasting pain relief and possibly prevented PHN.

\section{Case report \#1}

A 79-yr-old female developed a painful rash of the right scalp, ear and neck which was diagnosed as AHZ. Prodrome consisted of two days of severe rightsided headache before the rash appeared. She was started on acetaminophen with codeine and famciclovir $500 \mathrm{mg}$ po tid within $48 \mathrm{hr}$ of rash appearance. The pain was unremitting $(8 / 10)$ [all pain reported on the verbal analogue scale with 0 being no pain and 10 being the worst pain imaginable] and interfered with sleep. Carbamazepine $200 \mathrm{mg}$ bid was started at 14 days but caused severe side effects and no relief. She was seen in the Pain Management Clinic 17 days after the onset of the rash. Past medical history included a mechanical mitral valve, hypertension and transient ischemic attack. Other medications included warfarin, ranitidine, verapamil, furosemide, digoxin, and enalapril. Physical examination revealed a rash of C2, 3 and 4 dermatomes with crusting lesions and allodynia. A stellate ganglion block was considered, but was not performed due to the theoretical risk of hematoma and resulting airway compromise. Stopping the coumadin was considered but the risk of thrombosis of the valve was deemed greater than pro- ceeding with nerve blocks in the anticoagulated patient. A full discussion of risks and benefits of nerve blocks and other treatments occurred with the patient and her consent was obtained.

The transverse process of $\mathrm{C} 3$ could easily be palpated; therefore, a deep cervical plexus block was performed on the right with a 23 -gauge one-inch needle using bupivacaine $0.25 \%$ with $1: 400,000$ epinephrine $(10 \mathrm{~mL})$ and methylprednisolone acetate $30 \mathrm{mg}$. The needle was advanced to the transverse process, withdrawn slightly and injection was performed after negative aspiration. A greater occipital nerve block was also performed on the right with a 25 -gauge $11 / 2$-inch needle, using bupivacaine $0.25 \%$ with $1: 400,000$ epinephrine $(5 \mathrm{~mL})$ with methylprednisolone $10 \mathrm{mg}$. The $s c$ injection was performed adjacent to the artery along the superior nuchal ridge. Sensory block of C 2, 3, 4 dermatomes resulted. There were no complications. Pain relief was immediate and total (pain score 0/10). Pain had not recurred when seen one week later in the clinic or when called for telephone follow-up one year later. She stopped her analgesics immediately.

\section{Case report \#2}

A 73-yr-old female presented with a seven-day history of a painful $(8 / 10)$ rash on her left scalp, ear and neck. Prodrome consisted of two days of left-sided headache before the rash appeared. Pain was unrelieved by oxycodone and her sleep was affected. Famciclovir 500 mg po tid was prescribed at $\mathbf{5 2}$ hr. Her medications included estrogen and etidronate disodium calcium carbonate. Past medical history included osteoarthritis and Meniere's disease. Physical examination revealed a vesicular rash on the left cervical 2,3 and 4 dermatomes. The patient was fully informed of the risks and benefits and her consent was obtained.

Three separate injections were performed using a total volume of $20 \mathrm{~mL}$ of bupivacaine $0.5 \%$ with 1:200,000 epinephrine and methylprednisolone 40 mg: 1) the left greater occipital nerve was blocked with $4 \mathrm{~mL}$ using a 25 -gauge $1 \mathrm{l} / 2$ inch needle; 2 ) the left cervical root was blocked at C3 with $8 \mathrm{~mL}$ injected through a 23-gauge one-inch needle; and 3) the left $\mathrm{C} 4$ nerve root was blocked with $8 \mathrm{~mL}$ using a 23gauge one-inch needle. These injections produced sensory block of $\mathrm{C} 2,3,4$ dermatomes and total pain relief $(0 / 10)$. The technique was as described in Cousins and the same as in case \#l and is described in the textbook by Cousins and Bridenbaugh. ${ }^{5}$

The patient experienced transient dizziness, hoarse voice, and Horner's syndrome. Blood pressure before the block was $129 / 75 \mathrm{mmHg}$ and heart rate 91 beats. $\mathrm{min}^{-1}$. Blood pressure afterwards was $170 / 80$ 
$\mathrm{mmHg}$ and heart rate 80 beats. $\mathrm{min}^{-1}$. The side effects resolved in a few hours and she remained pain free $(0 / 10)$ the next day and at telephone follow-up three and 12 months later. She stopped oxycodone immediately. A mild sensation of itching in the left neck persisted for two weeks.

\section{Discussion}

We were surprised that the cases presented displayed complete and lasting relief from a single treatment with nerve blocks, but others have presented similar results. Winnie and Hartwell found that one third of patients with symptoms of less than two weeks got permanent complete relief from one block. ${ }^{4}$

Like much of the pain literature there are few wellcontrolled trials of nerve blocks in the prevention of PHN. In 1938 Rosenak published the first case report of nerve blocks for treatment of $\mathrm{AHZ}$ and postulated the subsequent prevention of PHN. ${ }^{6}$ August Colding pioneered the work on blocks in acute zoster and PHN in case reports. ${ }^{7}$ Tenicela randomly assigned 20 patients with AHZ to sympathetic nerve blocks or placebo. ${ }^{8}$ The local anesthetic was effective in resolving acute pain in $90 \%$ of patients, while placebo was effective in $20 \%$. Pasqualucci and colleagues showed epidural local anesthetic and steroids were more effective in preventing PHN than acyclovir and oral steroids. ${ }^{9}$ Six hundred adults over 55 with a rash of less than seven days duration and severe pain of AHZ were randomized to receive oral acyclovir and prednisolone or epidural bupivacaine and prednisolone over periods from seven to 21 days. The incidence of pain after one year was $22.2 \%$ in the oral medication group $v s 1.6 \%$ in the epidural group.

Wu reviewed the use of sympathetic nerve blocks in AHZ and PHN. ${ }^{10}$ Sympathetic blocks reduced the duration of pain associated with $\mathrm{AHZ}$ but it was unclear if PHN was prevented. He recommended that "in patients with AHZ who have severe pain that cannot be readily controlled by other means, sympathetic nerve blocks may be used to provide pain relief, and in so doing, possibly lessen the likelihood that PHN will develop". Johnson would agree: "it is likely that sympathetic or somatic nerve blocks during the acute phase of herpes zoster may not only control the acute pain but also reduce PHN".

Most authors would agree that nerve blocks do not provide lasting relief in established PHN. Injection of corticosteroids has been suggested to be of some benefit. Kotani published remarkable results following the intrathecal injection of methylprednisolone in established PHN of more than one year duration - even for cervical dermatomes. ${ }^{11}$ Forrest recommended epidur- al corticosteroids in PHN but his study is weakened by the lack of control subjects. ${ }^{12}$

Is it possible the pain resolution in these two cases was spontaneous and had nothing to do with the nerve blocks? Mayo Clinic data for patients over $70 \mathrm{yr}$ of age found pain at more than one month in $73.8 \%$ and at more than one year in $47.5 \%{ }^{13}$ A prospective evaluation of 1,778 patients with $\mathrm{AHZ}$ identified predictors of development of PHN to be patients who are older (over 50), patients who have had a prodrome, or who have severe rash or severe acute pain and patients that have severe pain. ${ }^{14}$ The expected incidence of PHN (pain at one month) in this age group varies from 48 to $75 \% .{ }^{13}$ Although impossible to predict in our two specific cases, having all the risk factors would place them at a higher incidence of developing PHN. Even if remission were about to occur in these patients it would be unlikely to occur so completely and suddenly if it were unrelated to the nerve blocks.

Therapy of AHZ has traditionally focused on antiviral agents and symptomatic relief. Anti-viral agents in the first 48 to $72 \mathrm{hr}$ decrease the occurrence of PHN but may have a limited effect on acute pain. ${ }^{15}$ Anti-viral therapy does not prevent PHN in all patients. Almost $20 \%$ of all patients $>50 \mathrm{yr}$ continue to have pain six months after the rash onset, despite treatment with famciclovir or valaciclovir beginning $\leq$ $72 \mathrm{hr}$ after the onset of the rash. ${ }^{16}$ Gabapentin is effective in $\mathrm{PHN}^{17}$ but the literature is sparse in regards to its use in AHZ. ${ }^{18}$ Amitriptyline may reduce the incidence of PHN when given during AHZ but is often poorly tolerated in the elderly. In Bowsher's study $16 \%$ of patients over $60 \mathrm{yr}$ of age who started amitriptyline $25 \mathrm{mg}$ daily within $48 \mathrm{hr}$ of rash had PHN at six months (vs $35 \%$ in the placebo group). ${ }^{19}$ Oral steroids may add to the benefit of anti-viral therapy for reducing the pain of AHZ but have no effect on the development of PHN. ${ }^{3}$ A lidocaine patch ${ }^{20}$ and EMLA $\mathrm{cream}^{21}$ may help in PHN and AHZ. Oral oxycodone, meperidine and methadone all have NMDA-antagonist effects and may treat the acute pain better than other narcotics that do not. ${ }^{22}$

Interventions that decrease pain, inflammation and tissue damage during the acute phase of herpes zoster may attenuate peripheral nociceptor sensitization and central hyperactivity. ${ }^{3}$ A similar mechanism underlies much of the research evaluating the prevention of lasting changes in spinal nociception in surgical patients. ${ }^{23}$ The inclusion of steroid in the block may decrease neuronal inflammation associated with the acute attack or may exert a membrane stabilizing effect on c-fibre transmission. ${ }^{24}$ A study of blocks using a local anesthetic with and without steroid needs to be performed to 
determine the benefit of steroids. In theory, the closer to the nerve damage the local anesthetic and the steroid are placed, the more beneficial the effect. ${ }^{24}$ However a peripheral nerve block has been shown effective in other neuropathic pain conditions in temporarily terminating pain and may be of use in AHZ. Whether sympathetic or somatic blocks are superior is unknown. Both have been shown to be efficacious. Somatic nerves were primarily blocked in both cases presented. However the second patient presented an unexpected sympathetic block also and it is possible this contributed to her relief. This patient developed transient dizziness and hypertension, possibly from the systemic absorption of epinephrine. The $0.5 \%$ concentration of bupivacaine is not necessary for these blocks and may have contributed to the dizziness.

There may be a concern about spreading infection by injecting in the rash area. Although secondary bacterial skin infection can occur in AHZ, a Medline search from 1966 to March 2004 using the keywords "herpes zoster / shingles / nerve block / adverse events / infection / complications / contraindications" revealed no block related spread of infection. Similarly, as regards the risk of hematoma in the neck with stellate or deep cervical plexus block in an anticoagulated patient, a Medline search from 1966 to March 2004 using the keywords "nerve block / anticoagulation / coumadin / stellate / hematoma / complications / cervical plexus" revealed nothing relevant. Stoneham's 1999 review describes hematoma following deep cervical plexus block as "rarely a significant problem". ${ }^{25}$

AHZ and PHN are common and painful conditions in our aging population. While we await an effective prevention strategy, the prompt treatment of patients suffering from $\mathrm{AHZ}$ and $\mathrm{PHN}$ is a compassionate goal. This report highlights two cases where the early treatment of $\mathrm{AHZ}$ resulted in lasting pain relief without progression to PHN. Johnson stated "(For blocks) to become practicable, we will certainly need to refine predictors so as to permit such specificity and sensitivity that a relatively small group of high risk patients can be identified. Education of patients to present early, and of primary care physicians to refer to specialist units, would be essential" ${ }^{26}$ There exists a notion that the pain clinic will be overwhelmed by patients with AHZ. This should not occur if only high-risk cases are accepted and may be compensated by a reduction in the caseload associated with chronic PHN. Future research and collaboration between primary care physicians and pain specialists may lead to improved outcomes in these debilitating conditions.

\section{Acknowledgements}

Thanks to Dr. Greg Bryson, Dr. John Penning for manuscript review and M. L Crossan and others for secretarial assistance.

\section{References}

1 Rowbotham MC, Petersen KL. Zoster-associated pain and neural dysfunction. Pain 2001; 93: 1-5.

2 Bhala BB, Ramamoorthy C, Bowsher D, Yelnoorker KN. Shingles and postherpetic neuralgia. Clin J Pain 1988; 4: 169-74.

3 Johnson $R W$. Consequences and management of pain in herpes zoster. J Infect Dis 2002; 186(Suppl 1): S83-90.

4 Winnie AP, Hartwell PW. Relationship between time of treatment of acute herpes zoster with sympathetic blockade and prevention of post-herpetic neuralgia: clinical support for a new theory of the mechanism by which sympathetic blockade provides therapeutic benefit. Reg Anesth 1993; 18: 277-82.

5 Murphy TM. Somatic blockade of the head and neck. In: Cousins MJ, Bridenbaugh PO (Eds). Neural Blockade in Clinical Anesthesia and Management of Pain, 3rd ed. Philadelphia: Lippincott-Raven; 1998: 508-9.

6 Rosenak S. Procaine injection treatment of herpes zoster. Lancet 1938; 1056-8.

7 Colding $A$. The effect of regional sympathetic blocks in the treatment of herpes zoster. A survey of 300 cases. Acta Anaesthesiol Scand 1969; 13: 133-41.

8 Tenicela $R$, Lovaski D, Eaglstein W. Treatment of herpes zoster with sympathetic nerve blocks. Clin J Pain 1985; 1: 63-7.

9 Pasqualucci A, Pasqualucci V, Galla F, et al. Prevention of post-herpetic neuralgia: acyclovir and prednisolone versus epidural local anesthetic and methylprednisolone. Acta Anaesthesiol Scand 2000; 44: 910-8.

$10 W u C L$, Marsh A, Dworkin RH. The role of sympathetic nerve blocks in herpes zoster and postherpetic neuralgia. Pain 2000; 87: 121-9.

11 Kotani N, Kushikata T, Hashimoto H, et al. Intrathecal methylprednisolone for intractable postherpetic neuralgia. N Engl J Med 2000; 343: 1514-9.

12 Forrest JB. The response to epidural steroid injections in chronic dorsal root pain. Can Anaesth Soc J 1980; 27: 40-6.

13 de Moragas JM, Kierland RR. The outcome of patients with herpes zoster. Arch Dermatol 1957; 75: 193-6.

14 Dworkin RH, Nagasako EM, Johnson RW, Griffin DR. Acute pain in herpes zoster: the famciclovir database project. Pain 2001; 94 :113-9.

15 Tyring S, Barbarash RA, Nablik JE, et al. Famciclovir for the treatment of acute herpes zoster: effects on 
acute disease and postherpetic neuralgia. A randomized, double-blind, placebo-controlled trial.

Collaborative Famciclovir Herpes Zoster Study Group. Ann Intern Med 1995; 123: 89-96.

16 Dworkin RH, Schmader KE. Treatment and prevention of postherpetic neuralgia. Clin Infect Dis 2003; 36: 877-82.

17 Rowbotham M, Harden N, Stacey B, Bernstein P, Magnus-Miller L; Gabapentin Postherpetic Neuralgia Study Group. Gabapentin for the treatment of postherpetic neuralgia: a randomized controlled trial. JAMA 1998; 280: 1837-42.

18 Filadora VA, Sist TC, Lema MJ. Acute herpetic neuralgia and postherpetic neuralgia in the head and neck: response to gabapentin in five cases. Reg Anesth Pain Med 1999; 24: 170-4.

19 Bowsher D. The effects of pre-emptive treatment of postherpetic neuralgia with amitriptyline: a randomized, double-blind, placebo-controlled trial. J Pain Symptom Manage 1997; 13: 327-31.

20 Campbell BJ, Rowbotham M, Davies PS, Jacob P III, Benowitz NL. Systemic absorption of topical lidocaine in normal volunteers, patients with post-herpetic neuralgia, and patients with acute herpes zoster. J Pharm Sci 2002; 91: 1343-50.

21 Stow PJ, Glynn CJ, Minor B. EMLA cream in the treatment of post-herpetic neuralgia. Efficacy and pharmacokinetic profile. Pain 1989; 39: 301-5.

22 Watson CP, Babul N. Efficacy of oxycodone in neuropathic pain. A randomized trial in postherpetic neuralgia. Neurology 1998; 50: 1837-41.

23 Woolf CJ. Recent advances in the pathophysiology of acute pain. Br J Anaesth 1989; 63: 139-46.

24 Johansson A, Bennett GJ. Effect of local methylprednisolone on pain in a nerve injury model. A pilot study. Reg Anesth 1997; 22: 59-65.

25 Stoneham MD, Knighton JD. Regional anaesthesia for carotid endarterectomy. Br J Anaesth 1999; 82: 910-9.

26 Johnson $R W$. Prevention of post-herpetic neuralgia: can it be achieved? Acta Anaesthesiol Scand 2000; 44: 903-5. 